\title{
Comunicação
}

[Communication]

\section{Inclusão de casca de pinhão-manso em dietas de ovinos: consumo voluntário e caracterização de quadro toxicológico}

[Fruit shell from Jatropha curcas including in sheep diets: a nutritional assessment and toxicological characterization]

\author{
V.L. Araújo ${ }^{1}$, S.S. Brito ${ }^{2}$, J.N.M. Neiva ${ }^{1}$, P.M. Barreto ${ }^{2}$, O.R. Ferreira ${ }^{2}$, F.G. Lima $^{3}$, A.T. Ramos ${ }^{2}$, \\ M.C.S. Fioravanti ${ }^{4}$, V.M. Maruo ${ }^{1}$, A.C.H. Ferreira ${ }^{1}$ \\ ${ }^{1}$ Escola de Medicina Veterinária e Zootecnia - UFT - Araguaína, TO \\ ${ }^{2}$ Aluno de pós-graduação - UFT - Araguaína, TO \\ ${ }^{3}$ Aluna de pós-graduação - UFG - Goiânia, GO \\ ${ }^{4}$ Escola de Veterinária - UFG - Goiânia, GO
}

No Brasil, o consumo de óleo diesel encontra-se em torno dos 40 bilhões de litros por ano, e destes cerca de 5,3 bilhões são oriundos de importação. O biodiesel é um combustível renovável e menos poluente, utilizado para substituir parcial ou totalmente combustíveis fósseis, ou seja, o diesel de petróleo em caldeiras e em motores de ignição por compressão, automotivos, transportes e estacionários. A utilização dos biocombustíveis, com destaque ao biodiesel, além de ser um potencial substituinte do diesel de petróleo, é também uma alternativa para utilização de sementes de oleaginosas.

Diferentes tipos de matéria-prima podem ser utilizados na produção do biodiesel, como mamona, dendê, soja, girassol, pinhão-manso, batata-doce, amendoim, algodão, além de gordura animal, óleo e gorduras residuais. O processo químico de produção de biodiesel baseia-se na transesterificação, na qual um óleo vegetal reage com um álcool, em meio alcalino. O principal produto dessa reação é o biodiesel (éster de ácido graxo), enquanto a glicerina é o principal subproduto de valor agregado para a indústria cosmética e farmacêutica. No entanto, a produção do biodiesel também gera uma infinidade de subprodutos utilizados como fertilizantes, os quais adquirem maior valor agregado quando utilizados na alimentação animal. Porém, muito pouco ainda se sabe sobre o valor nutritivo e as porcentagens ótimas de inclusão desses resíduos na alimentação animal. O óleo representa entre 17 e $50 \%$ da produção total do biodiesel, sendo assim, a cada tonelada produzida, tem-se a produção de, no mínimo, uma tonelada de torta ou de fertilizante natural (Campos e Carmelio, 2006).

O pinhão-manso (Jatropha curcas) é uma planta da família das Euforbiáceas, como a mamona e a mandioca, a qual se destaca pelo seu potencial de produção de biodiesel. Nativa da América do Sul, é explorada com sucesso na América Central, Índia e África. A cultura é uma excelente opção para regiões carentes e tem se adaptado muito bem à região Norte do país. Produz cerca de duas toneladas de óleo por hectare, em terras de pouca fertilidade, arenosas, com climas desfavoráveis a várias culturas, necessitando, assim, de poucos cuidados. Devido às suas características, o pinhão-manso tem sido considerado como boa opção para sistemas de pequenas propriedades com mão de obra familiar (Haas e Mittelbach, 2000; Saturnino et al., 2005).

Na substituição ao óleo diesel, o pinhão-manso destaca-se, uma vez que produz $83,9 \%$ do valor calorífico do óleo diesel. Além disso, a produção do biodiesel a partir do fruto do pinhão-manso gera como subprodutos a casca do fruto do pinhão-manso, a qual é utilizada como carvão vegetal, e a torta de pinhão-manso, ambos com 
possibilidades de uso na alimentação animal. Entretanto, um dos principais inconvenientes da utilização de resíduos do pinhão-manso na alimentação animal é a presença de fatores antinutricionais (fitatos e inibidores de tripsina) e de princípios tóxicos (ésteres de forbol e curcina) (Gubitz et al., 1999; Makkar et al., 1998). No entanto, a torta de pinhão-manso, após detoxificada, pode ser também utilizada na alimentação animal. Porém, muito pouco ainda se conhece a respeito do valor nutritivo, como a digestibilidade de seus nutrientes, os níveis de inclusão na dieta e desempenho para animais (Saturnino et al., 2005).

O objetivo deste ensaio foi determinar a porcentagem ótima de inclusão da casca do fruto do pinhão-manso à dieta de ovinos, em substituição ao feno de capim-mombaça, avaliando-se o consumo de alimento e a ocorrência de alterações clínicas e histológicas.

As dietas foram fornecidas à vontade, com 5 a $10 \%$ de sobra do total fornecido, às nove e 17 horas. A casca utilizada foi obtida na empresa Biotins Energia, localizada em Paraíso do Tocantins/TO. Foram utilizados 20 ovinos SRD, machos, castrados, em delineamento inteiramente ao acaso, com quatro tratamentos e cinco repetições.

Os animais foram mantidos em gaiolas de metabolismo, e a previsão de duração do ensaio foi de 21 dias, sendo 14 dias para adaptação e cinco dias para determinação do consumo voluntário e determinação do quadro clínico. Ao $11^{\circ}$ dia do período de adaptação, um animal, do tratamento que continha $30 \%$ de casca de pinhão-manso, apresentou sintomatologia clínica característica de intoxicação e veio a óbito. Os demais foram mantidos sob condições experimentais predeterminadas. Ao $13^{\circ}$ dia, iniciou-se o período de coleta, que se prolongou por cinco dias para determinação do consumo voluntário. $\mathrm{Na}$ Tab.1, estão a composição bromatológica e a energia bruta dos alimentos utilizados.

Tabela 1. Composição bromatológica (na matéria seca) e energia bruta da casca do fruto do pinhão-manso e do feno de capim-mombaça

\begin{tabular}{cccccccc}
\hline & MS & PB & FDN & FDA & Lignina & EE & EB \\
\hline Casca de pinhão-manso & 92,56 & 9,39 & 62,80 & 57,14 & 7,92 & 5,91 & 3419,58 \\
Feno de capim-mombaça & 90,31 & 8,48 & 69,17 & 37,61 & 5,76 & - & - \\
\hline
\end{tabular}

Após a constatação de intoxicação, optou-se por sacrificar todos os animais ao final do período de coleta. Antes do sacrifício, foram realizados exames clínicos completos em todos os animais e foi coletado sangue para futuras análises hematológicas e bioquímicas.

Foi observada redução considerável no consumo de matéria natural à medida que houve aumento da inclusão da casca do fruto do pinhão-manso à dieta. Os valores médios foram de 1444,92, $298,48,191,45$ e $88,68 \mathrm{~g} /$ dia para a inclusão de 0 , 15,30 e $45 \%$ de casca do fruto do pinhão-manso na dieta, respectivamente. Essa redução do consumo de alimento pode estar relacionada à presença de fatores antinutricionais e/ou de princípios tóxicos, ainda não determinados na casca do fruto do pinhão-manso. Segundo Makkar et al. (1998), além dos componentes tóxicos como curcina, flavanoides e ésteres de forbol, o pinhão-manso também apresenta fatores antinutricionais como inibidores de tripsina e fitatos, responsáveis por redução do consumo e do valor nutritivo da planta. Aderibigbe et al. (1997) observaram que o tratamento do farelo de pinhão-manso com o calor foi uma alternativa eficiente para inativar os inibidores de tripsina no material. Além disso, esses autores observaram que o farelo de pinhão-manso parcialmente desengordurado apresentou maior porcentagem de degradabilidade in vitro do nitrogênio, ao utilizarem a técnica de produção de gases, quando submetido a $130^{\circ} \mathrm{C}$, durante 60 minutos, demonstrando a possibilidade de detoxificação do material.

O quadro clínico-patológico foi caracterizado por desordens digestivas, hepáticas, renais, pulmonares e cardíacas. Independentemente da porcentagem de inclusão da casca de pinhãomanso, todos os animais que receberam pinhãomanso na dieta apresentaram, mesmo que em 
diferentes graus, apatia, redução de apetite, redução do conteúdo e tensão ruminal, redução da motilidade ruminal, emagrecimento acentuado, consistência e tamanho de cíbalas alterados. Também foram observados aumento de linfonodos parotídeo, mandibular e retrofaríngeo (em graus variando de 1 a 5), secreção nasal e turgor de pele alterados, indicando diferentes graus de desidratação. Segundo Makkar et al. (1998), a baixa aceitação da planta como alimento seria devido à presença dos ésteres de forbol que estão presentes em elevadas quantidades nas variedades tóxicas de pinhão-manso. Os ésteres de forbol têm sido relacionados com alterações biológicas, como vômito, diarreia, tonturas, promoção de tumores, ativação plaquetária, aumento da mitogênese linfocítica e da resposta inflamatória, degranulação de neutrófilos, redução da fertilidade e reabsorção fetal (Goonasekera et al., 1995; Hass e Mittelbach, 2000).

À necropsia, em todos os grupos tratados, foram observados úlceras no abomaso, congestão nos intestinos, linfonodos mesentéricos edematosos, congestão hepática, flacidez no coração, congestão e edema pulmonar, com presença de espuma na traqueia. $\grave{A}$ microscopia, foi confirmada a presença de congestão e de edema pulmonar, e foram constatados infiltrado inflamatório no intestino, no fígado, no baço e nos pulmões, congestão hepática e colestase, com degeneração vacuolar dos hepatócitos, linfonodos mesentéricos edematosos, degeneração tubular e cristais de cálcio nos rins.

Resultados semelhantes foram encontrados por Abdel Gadir et al. (2003) em intoxicação experimental de caprinos com sementes de $J$. curcas. Os autores observaram extensa hemorragia e congestão e severa enterohepatonefrotoxicidade, as quais foram atribuídas aos constituintes ativos das sementes. Óleos purgantes, taninos, esteróis, terpenos e curcina foram isolados em estudos fitoquímicos das sementes, porém a alta concentração de ésteres de forbol presentes na semente de Jatropha foi identificada como sendo o principal agente tóxico responsável pela toxicidade de Jatropha (Adolf et al., 1984; Makkar et al., 1997; Kumar e Sharma, 2008).

A maioria dos estudos que avaliaram a toxicidade de $J$. curcas utilizou as sementes inteiras intactas ou após a extração de óleo. No presente estudo, foi utilizada a casca do fruto do pinhão-manso, que é extraída antes da obtenção das sementes. Sabe-se que as substâncias químicas se distribuem de forma variada nas diferentes partes das plantas. No caso de $J$. curcas, as partes aéreas possuem ácidos orgânicos, saponinas e taninos, a torta possui fitatos, saponinas e um inibidor de tripsina e as sementes possuem curcina, ésteres de forbol, esterases e lípase, contudo os constituintes da casca do fruto ainda permanecem obscuros (Kumar e Sharma, 2008).

Dessa forma, conclui-se que a casca do fruto do pinhão-manso não deve ser utilizada na suplementação de ovinos, nas porcentagens usadas neste estudo. Há que se conhecer melhor os constituintes da casca do fruto e detoxificar e/ou eliminar fatores antinutricionais no material, com a finalidade de usá-la na dieta de animais de produção.

Palavras-chave: intoxicação, ovino, pinhãomanso, Jatropha curcas, consumo

\begin{abstract}
The nutrients intake and histopathological occurrences were evaluated in sheep fed diets with increasing levels of inclusion $(0 \%, 15 \%, 30 \%$, and 45\%) of Jatropha curcas dried and crushed fruit shell in substitution to Mombaça grass hay. Twenty castrated male sheep were kept in metabolic cages and fed diets ad libitum (5 to 10\% scraps were allowed). At the end of the experiment, the animals were subjected to clinical examination and blood collection, followed by euthanasia and necropsy. The clinical and pathological disorders were characterized by digestive, lung, and heart alterations, with regressive changes affecting kidney and liver. Presence of fluid in the abdominal and pericardial cavities, intestine with little content or empty, reddish serosa, and hyperemic mucosa with streaks of blood were observed during necropsy; as well as edematous mesenteric lymph nodes; red, swollen, and firm lung (hepatization) with emphysema areas, suffusions in the serous of the rumen, and ulcers in the abomasum.
\end{abstract}


Histopathological analysis revealed congestion and pulmonary edema, congestion and vacuolar degeneration of hepatocytes, edematous mesenteric lymph nodes, tubular degeneration, and the presence of calcium crystals in the kidney. Thus, the collected data reveals that J. curcas fruit shell is toxic when added at different levels in sheep diet.

Keywords: intoxication, sheep, Jatropha curcas, intake

\section{AGRADECIMENTOS}

Ao CNPq, pelo financiamento do projeto. À CAPES, pela concessão de bolsas de mestrado. Ao programa PRODOC/CAPES, pela de bolsa de pós-doutoramento ao autor Adriano Tony Ramos. À Biotins Energia, pelo fornecimento da casca de pinhão manso utilizada no experimento.

\section{REFERÊNCIAS BIBLIOGRÁFICAS}

ABDEL GADIR, W.S.; ONSA, T.O.; ALI, W.E.M. et al. Comparative toxicity of Croton macrostachys, Jatropha curcas and Piper abyssinica seeds in Nubian goats. Small Rum. Res., v.48, p.61-67, 2003.

ADERIBIGBE, A.O.; JOHNSON, C.O.L.E.; MAKKAR, H.P.S. et al. N. Chemical composition and effect of heat on organic matter and nitrogen degradability and some antinutritional components of Jatropha meal. Anim. Feed Sci. Technol., v.67, p.223-243, 1997.

ADOLF, W.; OPFERKUCH, H. J.; HECKER, E. Irritant phorbol derivatives from four Jatropha species. Phytochemistry, v.23, p.129-132, 1984.

CAMPOS, A.; CARMELIO, E.C. Biodiesel e agricultura familiar no Brasil: resultados socioeconômicos e expectativas futuras. In: FERREIRA, J.R.; CRISTO, C.M.P.N (Coord.). $O$ futuro da indústria: biodiesel: coletânea de artigos. Brasília: MDIC-STI/IEL, 2006. 145p.
GOONASEKERA, M.M.; GUNAWARDANA, V.K.; JAYASENA, K. et al. Pregnancy terminating effect of Jatropha curcas in rats. J. Ethonopharmacol., v.47, p.117-123, 1995.

GUBITZ, G.M.; MITTELBACH, M.; TRABI, M. Exploitation of the tropical oil seed plant Jatropha curcas L. Bioresour. Technol., v.67, p.73-82, 1999.

HASS, W.; MITTELBACH, M. Detoxification experiments with the seed oil from Jatropha curcas L. Industr. Crops Prod., v.12, p.11-118, 2000.

KUMAR, A.; SHARMA, S. An evaluation of multipurpose oil seed crop for industrial uses (Jatropha curcas L.): A review. Industr.Crops Prod., v.28, p.1-10, 2008.

MAKKAR, H.P.S.; BECKER, K.; SPORER, F. et al. Studies on nutritive potential and toxic constituents of different provenances of Jatropha curcas. J. Agric. Food Chem., v.45, p.31523157, 1997.

MAKKAR, H.P.S.; ADERIBIGBE, A.O.; BECKER, K. Comparative evaluation of nontoxic and toxic varieties of Jatropha curcas for chemical composition, digestibility, protein degradability and toxic factors. Food Chem., v.62, p.207-215, 1998.

SATURNINO, H.M.; PACHECO, D.D.; KAKIKA, J. et al. Cultura do pinhão-manso (Jatropha curcas L.) Inf. Agropec., v.6, p.44-78, 2005. 